\title{
Quantitative proteomic study of the plasma reveals acute phase response and LXR/RXR and FXR/RXR activation in the chronic unpredictable mild stress mouse model of depression
}

\author{
CHUANGCHUANG YANG ${ }^{1-4^{*}}$, CHANJUAN ZHOU ${ }^{1,3,4^{*}}, \mathrm{JIE} \mathrm{LI}^{3,5^{*}}, \mathrm{ZHI} \mathrm{CHEN}^{2,3,5^{*}}$, \\ HAIYANG SHI ${ }^{1,3,4}$, WENSONG YANG ${ }^{1,3,4}$, YINHUA QIN ${ }^{3-5}$, LIN LÜ ${ }^{3,5}$, LIBO ZHAO ${ }^{1,3,4}$, \\ LIANG FANG ${ }^{1,3,4}$, HAIYANG WANG ${ }^{3,5}$, ZICHENG HU ${ }^{2,3,5}$ and PENG XIE II-3,5 $^{1-5}$ \\ ${ }^{1}$ Department of Neurology, Yongchuan Hospital of Chongqing Medical University, \\ Chongqing 402460; ${ }^{2}$ Department of Neurology, The First Affiliated Hospital of Chongqing Medical University; \\ ${ }^{3}$ Institute of Neuroscience and The Collaborative Innovation Center for Brain Science, Chongqing Medical University; \\ ${ }^{4}$ Key Laboratory of Laboratory Medical Diagnostics of Education, Department of Laboratory Medicine, \\ Chongqing Medical University; ${ }^{5}$ Chongqing Key Laboratory of Neurobiology, Chongqing 400016, P.R. China
}

Received July 25, 2017; Accepted October 13, 2017

DOI: $10.3892 / \mathrm{mmr} .2017 .7855$

\begin{abstract}
Major depressive disorder is a severe neuropsychiatric disease that negatively impacts the quality of life of a large portion of the population. However, the molecular mechanisms underlying depression are still unclear. The pathogenesis of depression involves several brain regions. However, most previous studies have focused only on one specific brain region. Plasma and brain tissues exchange numerous components through the blood-brain barrier. Therefore, in the present study, plasma samples from control (CON) mice and mice subjected to chronic unpredictable mild stress (CUMS) were used to investigate the molecular pathogenesis of depression, and the association between the peripheral circulation and the central nervous system. A total of 47 significant differentially expressed proteins were identified between the CUMS and CON group by an isobaric tag for relative and absolute quantitation (iTRAQ) coupled with tandem mass spectrometry approach. These 47 differentially expressed proteins were analyzed with ingenuity pathway analysis (IPA) software. This revealed that the acute phase response, LXR/RXR and FXR/RXR activation, the complement system and the intrinsic prothrombin activation pathway were significantly changed. Four of the significant
\end{abstract}

Correspondence to: Professor Peng Xie, Department of Neurology, The First Affiliated Hospital of Chongqing Medical University, 1 Youyi Road, Chongqing 400016, P.R. China

E-mail: xiepeng@cqmu.edu.cn

*Contributed equally

Key words: major depressive disorder, chronic unpredictable mild stress, plasma, isobaric tag for relative and absolute quantitation, proteomics differentially expressed proteins (lipopolysaccharide binding protein, fibrinogen $\beta$ chain, $\alpha-1$ antitrypsin, and complement factor $\mathrm{H}$ ) were validated by western blotting. the present findings provide a novel insight into the molecular pathogenesis of depression.

\section{Introduction}

Major depressive disorder (MDD), a severely debilitating mental disease, negatively affects the quality of life of a substantial percentage of the world population, and is associated with a lifetime morbidity of $4.4-20 \%$ (1). It is predicted that MDD will be the second most common illness in 2020, according to the 1990 Global Burden of Illness list. It is estimated that the economic burden of depression was $\$ 52.9$ billion in 1990 and $\$ 83.1$ billion in 2000 in the United States $(2,3)$. Therefore, much attention has been given to depression research worldwide. Over the last few decades, many pathogenetic mechanisms have been put forward for MDD (4). However, the molecular mechanisms of MDD remain largely unknown. It is therefore urgent to elucidate the underlying mechanisms of MDD.

To gain insight into the pathogenesis of depression, our team previously used a proteomics approach on human plasma. However, the differential proteins in Xu et al (5) were different from those in Yang et al (6) and Song et al (7). A possible reason for the lack of concordance is variability in the factors that cause depression. The pathogenesis of depression may therefore differ among patients, accounting for the varying proteomic changes. Furthermore, some patients might have taken antidepressants that affect the metabolism of proteins in plasma (8). Therefore, we established a mouse model of chronic unpredictable mild stress (CUMS) to acquire more robust data (9). In this model, mice in the CUMS group are exposed to the same stressors at the same time. Both physical and mental stressors are given to imitate the risk factors that depressive patients encounter in daily life. Hence, the CUMS 
model might well mimic human depression, and plasma from CUMS mice might help clarify the molecular changes in the disease.

MDD is a mental illness, and therefore, cerebrospinal fluid (CSF) and brain tissue samples might be better for proteomic studies investigating the molecular mechanisms of MDD; however, such samples are not practically accessible for living human subjects. In contrast, plasma samples can be obtained easily. Moreover, the pathogenesis of depression involves several brain regions, while most published papers only examine one region at a time (10-12). CSF, plasma and brain tissue exchange their molecular components through the blood-brain and CSF-brain barriers, which suggests that some proteins might be exchanged between the central nervous system and the peripheral circulation $(13,14)$. Therefore, plasma samples might be better for examining the pathogenesis of depression (15).

Proteomics is a hypothesis-free approach, and it is a useful tool for discovering novel molecules involved in the pathogenesis of disease. It has been applied in a wide range of diseases, such as depression, schizophrenia and other psychiatric illnesses (16). In the present study, isobaric tags for relative and absolute quantitation (iTRAQ) was employed for identifying proteins differentially expressed between CON and CUMS mice. Furthermore, some of the proteins involved in the significantly changed pathways were validated by western blotting.

\section{Materials and methods}

Animals. A total of 40 adult male mice (8-10 weeks of age) were bought from Chongqing Medical University's animal facility. Unless indicated otherwise, the mice were maintained under standard conditions $(12 \mathrm{~h}-12 \mathrm{~h}$ light-dark cycle, lights on from 07:00 a.m. to 07:00 p.m.; temperature: $23 \pm 1^{\circ} \mathrm{C}$; relative humidity of $40-60 \%$; food and water available ad libitum). Chongqing Medical University's Ethics Committee approved all procedures, which were in accordance with the National Institutes of Health's Animal Research Guide. Efforts were made to reduce the number of deaths and to minimize suffering. (9).

CUMS protocol. The CUMS protocol was carried out according to our previously published papers, with some minor modifications. After adaptation and sucrose preference training, each lasting a week, mice were isolated into two groups: CUMS group $(n=20)$ and CON group $(n=20)$. The mice in the CUMS group were subjected to various repeated unpredictable mild stressors for 4 weeks, during which the sucrose preference test was performed. Minor stress sources included deprivation of water and food, paired housing, wet bedding, $45^{\circ}$ cage tilt, night lighting, white noise, strobe, and odor exposure. All stressors were applied in a random order, and we did not repeat the same stressors over 2 consecutive days.

Behavioral test. The sucrose preference test (SPT) is one of the most important tests for evaluating depressive symptoms in mice. After 1 week of adaptation to the environment, each mouse was trained using two bottles of water for 1 week, one with $1 \%$ sucrose solution and the other with tap water. According to the baseline of sucrose preference, the mice were segregated into two groups with no significant difference. One group was exposed to CUMS stressors, while the other group was kept under standard conditions. Sucrose preference was measured starting at 8 am every Sunday morning for $24 \mathrm{~h}$. During the test, the mice were placed in separate cages with equal access to the two bottles. The location of the two bottles was changed randomly to avoid position preference. The total weight consumed by the mouse was measured. Sucrose preference (SP) was calculated as follows: $\mathrm{SP}=$ (weight of $1 \%$ sucrose solution consumed/[the weight of $1 \%$ sucrose solution consumed + the weight of water consumed]) $\mathrm{x} 100 \%$.

Open field testing was used to assess space exploration behavior. Before the test, the mice were placed in the experimental room for $30 \mathrm{~min}$. The experiment was carried out in a soundproof room from 8 am to $1 \mathrm{pm}$. Only one mouse was placed in the open field test apparatus $(44.5 \times 44.5 \times 45 \mathrm{~cm})$ at a time, and allowed to freely explore the field for $6 \mathrm{~min}$. The behavior was recorded and analyzed with an automatic video-tracking system (Smart, Panlab SL, Barcelona, Spain). The box was thoroughly cleaned with alcohol after each trial.

The forced swim test, also known as the behavioral despair test, which evaluates the rodent's response to the threat of drowning, was carried out in the experimental room from $8 \mathrm{am}$ to $1 \mathrm{pm}$. In a separate test, the mouse was placed in the apparatus (height, $30 \mathrm{~cm}$; diameter, $15 \mathrm{~cm}$ ) for $5 \mathrm{~min}$, and the pool was filled with tap water. The depth of the water was about $15 \mathrm{~cm}$, and the water temperature was about $23 \pm 1^{\circ} \mathrm{C}$. After each trial, the water was replaced with fresh water. Behavioral recording and analysis were performed using the Smart system mentioned above.

Immunodepletion of high abundance plasma proteins. Frozen plasma samples from the two groups $(\mathrm{CON}(\mathrm{n}=20)$ and CUMS $(n=20)$ were thawed, and equal-volume samples from six or seven mice $(6,7)$ for each group were pooled to minimize the effect of individual variation (each group therefore generated three pooled samples). The pooled plasma samples were immunodepleted of high abundance plasma proteins using a Multiple Affinity Removal LC Column-Mouse 3 (Agilent Technologies, Inc., Santa Clara, CA, USA). The procedure was carried out according to the manufacturer's instructions. To evaluate the removal of high abundance proteins, samples of non-immunodepleted plasma and immunodepleted plasma were separated on $12.5 \%$ SDS-PAGE gels and then stained with Coomassie Blue $(5,17)$.

iTRAQ labeling, and strong cation exchange (SCX) fractionation. After removal of high abundance proteins from plasma, the samples were quantified using the BCA assay. Then, 300- $\mu \mathrm{g}$ samples of total protein for each group were taken out for analysis. To these samples, $25 \mu 1$ of SDT solution was added, and then DTT solution to a final concentration of $100 \mathrm{mM}$. These samples were then placed in a boiling water bath for $5 \mathrm{~min}$ and then cooled to room temperature. Thereafter, $200 \mu$ l of UA buffer (8 M urea, $150 \mathrm{mM}$ Tris-HCl, $\mathrm{pH}$ 8.0) was added, and the samples were then centrifuged at $14,000 \mathrm{x}$ g for 
$30 \mathrm{~min}$ in a $30-\mathrm{kd}$ ultrafiltration centrifuge tube. Subsequently, $200 \mu \mathrm{l}$ of UA buffer was added to the samples and centrifuged at $14,000 \mathrm{x} \mathrm{g}$ for $30 \mathrm{~min}$. After discarding the filtrate, $100 \mu \mathrm{l}$ of IAA (50 mM IAA in UA) was added. The solution was shaken at $600 \mathrm{rpm}$ for $1 \mathrm{~min}$, followed by a $45 \mathrm{~min}$ incubation at room temperature. The samples were then centrifuged at $14,000 \mathrm{xg}$ for $30 \mathrm{~min}$. Thereafter, $100 \mu \mathrm{l}$ of UA buffer was added to the concentrate and centrifuged at 14,000 x g, twice, $30 \mathrm{~min}$ each. After discarding the filtrate, $100 \mu \mathrm{l}$ of $25 \mathrm{mM} \mathrm{ABC}$ was added, and the solution was centrifuged at $14,000 \mathrm{x}$ g for $30 \mathrm{~min}$. After discarding the filtrate, $40 \mu \mathrm{l}$ of trypsin buffer ( $6 \mu \mathrm{g}$ trypsin in $40 \mu 1100 \mathrm{mM}$ ABC) was added. This solution was shaken at $600 \mathrm{rpm}$ for $1 \mathrm{~min}$ followed by a $16-18$-hour incubation at $37^{\circ} \mathrm{C}$. Then, $40 \mu \mathrm{l}$ of $25 \mathrm{mM}$ ABC was added to the previous solution and centrifuged at $14,000 \times \mathrm{g}$ for $30 \mathrm{~min}$. Subsequently, $0.1 \%$ TFA solution was added, and the $\mathrm{OD}_{280}$ was measured after desalting on a C18 cartridge (Sigma-Aldrich; Merck KGaA, Darmstadt, Germany). Samples containing $100 \mu \mathrm{g}$ of protein were labeled with the AB kit (iTRAQ Reagent-8plex Multiplex kit (AB Sciex, Foster City, CA, USA) according to the manufacturer's protocol $(113,114,115$ for the CON group; 116, 117, 118 for the CUMS group). The parameters used for SCX fractionation were as follows: AKTA Purifier 100 (GE Healthcare, Chicago, IL, USA), polysulfoethyl 4.6x100 mm column $(5 \mu \mathrm{m}$, $200 \AA$ ) (PolyLC Inc., Columbia, MD, USA), SCX Buffer A $\left(10 \mathrm{mM} \mathrm{KH}_{2} \mathrm{PO}_{4} \mathrm{pH} 3.0,25 \%\right.$ CAN), SCX Buffer B (10 mM $\mathrm{KH}_{2} \mathrm{PO}_{4} \mathrm{pH} 3.0,500 \mathrm{mM} \mathrm{KCl}, 25 \% \mathrm{CAN}$ ). The peptide fragments after iTRAQ labeling were mixed and subjected to SCX fractionation. For each test, 33 fractions were collected from each group and then combined into ten pools according to the SCX chromatogram, which were next desalted with a C18 cartridge (66872-U; Sigma-Aldrich; Merck KGaA) (9).

Liquid chromatography-tandem mass spectrometry. Each sample was separated using a nano-flow velocity HPLC liquid system, Easy nLC (Thermo Fisher Scientific, Inc., Waltham, MA, USA), and $0.1 \%$ formic acid aqueous solution (buffer $\mathrm{A}$ ) and $0.1 \%$ formic acid acetonitrile aqueous solution (acetonitrile 84\%) (buffer B) were used in the experiment. The column was equilibrated with $95 \%$ buffer A. Then, samples were loaded with the autosampler onto the Thermo Scientific EASY-column (2 cm x100 $\mu \mathrm{m}, 5 \mu \mathrm{m}-\mathrm{C} 18)$ and separated on an analytical column (Thermo Scientific EASY-column, $75 \mu \mathrm{m} \times 100 \mathrm{~mm}, 3 \mu \mathrm{m}-\mathrm{C} 18$ ) at a flow rate of $300 \mathrm{nl} / \mathrm{min}$. The liquid phase parameters were as follows: 0 to $55 \mathrm{~min}$, buffer B from 0 to $50 \%$ with a linear gradient; 55 to $57 \mathrm{~min}$, buffer B from 50 to $100 \%$ with a linear gradient; 57 to $60 \mathrm{~min}$, buffer B maintained at $100 \%$. After separation by capillary high performance liquid chromatography, each sample was analyzed by mass spectrometry using a Q-Exactive mass spectrometer (Thermo Finnigan, San Jose, CA, USA). The parameters were as follows: Analysis time, $60 \mathrm{~min}$; detection method, positive ion; parent ion scanning range, $300-1,800 \mathrm{~m} / \mathrm{z}$; primary mass spectrometry resolution, 70,000 at $\mathrm{m} / \mathrm{z}$ 200; AGC target, 3e6; primary maximum IT, $10 \mathrm{~ms}$; number of scan ranges, 1; dynamic exclusion, $40.0 \mathrm{~s}$. The mass/charge ratio of the fragments of the polypeptide and polypeptide were collected using the following parameters: MS2 activation type, HCD; isolation window, $2 \mathrm{~m} / \mathrm{z}$; secondary mass spectrometry resolution,
17,500 at $\mathrm{m} / \mathrm{z} 200$; microscans, 1; secondary maximum IT, $60 \mathrm{~ms}$; normalized collision energy, $30 \mathrm{eV}$; underfill ratio, $0.1 \%$. Subsequently, the original data was processed with Mascot 2.2 and Proteome Discoverer 1.4 software packages (Thermo Fisher Scientific, Inc.) for identification and quantitative analysis. The database was downloaded from Unipart (uniprot_mouse_78469_20150825.fasta, including 78649 series, downloaded on 2015-07-25). Peptide FDR was set at $\leq 0.01(9)$.

Ingenuity pathway analysis (IPA). IPA software has been widely used in proteomics research $(9,11)$. To determine the significant canonical pathways, networks of interacting proteins and models of functions and diseases, we uploaded the differentially expressed protein lists (with UniProt accession) and the directions of change of these proteins onto the IPA server (Qiagen, Inc., Valencia, CA, USA). All these analyses used Fisher's exact test with a $\mathrm{P}<0.5$.

Western blotting. Frozen plasma samples were thawed and diluted 50 times using $1 \mathrm{X}$ PBS and $1 \mathrm{X}$ loading buffer. The volume of the loading buffer was one-fourth of the total volume. The proteins were denatured at $100^{\circ} \mathrm{C}$ for $10 \mathrm{~min}$. Following SDS-PAGE, the proteins were transferred to PVDF membranes. After blocking in 5\% non-fat milk power in TBST for $2 \mathrm{~h}$ at room temperature, the PVDF membrane was incubated for $10 \mathrm{~h}$ at $4^{\circ} \mathrm{C}$ with the following primary antibodies: Anti-lipopolysaccharide binding protein (LBP) antibody (1:500; Ruiying Biological, http://www.rlgene.com/), anti-fibrinogen $\beta$ chain (FGB) antibody (1:1,000; Sangon Biotech Co., Ltd., Shanghai, China), anti- $\alpha-1$ antitrypsin (SERPINA1) antibody (1:1,000; Abcam, Cambridge, UK), anti-complement factor $\mathrm{H}$ antibody (CFH) (1:500; Abcam). After three washes with THST, the membrane was incubated with anti-sheep or anti-rabbit secondary antibody $(1: 10,000)$ at room temperature for $2 \mathrm{~h}$, and then the membrane was washed another three times with TBST (10 min each). The relative intensity of each protein was calculated with Quantity One software (version 4.6.7; Bio-Rad Laboratories, Inc., Hercules, CA, USA).

Statistical analysis. All of the data results were presented as mean \pm standard deviation. Analysis of sucrose preference and body weight of mice was performed using ANOVA method. Behavioral data of the two groups of mice and the data of western blotting were analyzed by Student's t-test. All data shown in this study were calculated by SPSS21.0 (IBM Corp., Armonk, NY, USA) used in our previous study. The threshold for statistical significance was set at $\mathrm{P}<0.05$.

\section{Results}

Assessment of the CUMS mouse model. The CUMS mouse model was evaluated using the sucrose preference test (SPT), body weight measurement, the forced swim test (FST), and the open-field test (OFT). Given that the plasma samples used in this study were collected from the same batch of mice used in our previous publication (9), the results are only briefly described here. Body weight in the CUMS group was significantly lower than in the CON group after treatment $(\mathrm{P}=0.001)$. 
Table I. Significant differentially expressed proteins identified by an iTRAQ coupled with LC-MS/MS method.

\begin{tabular}{|c|c|c|c|c|c|}
\hline $\begin{array}{l}\text { UniProt } \\
\text { accession }\end{array}$ & $\begin{array}{c}\text { Gene } \\
\text { symbol }\end{array}$ & Name & $\begin{array}{l}\text { Unique } \\
\text { peptides }\end{array}$ & CUMS/CON & $\begin{array}{c}\text { t-test } \\
\text { P-value }\end{array}$ \\
\hline Q6LD55 & APOA2 & APOAII & 2 & 0.23 & 1.19E-03 \\
\hline A2APX3 & CST3 & Cystatin-C (Fragment) & 2 & 0.44 & 3.28E-02 \\
\hline Q9EQI5 & РPBP & $\begin{array}{l}\text { Chemokine (C-X-C motif) } \\
\text { ligand } 7 \text {, isoform CRA_b }\end{array}$ & 2 & 0.6 & $5.08 \mathrm{E}-03$ \\
\hline P98086 & C1QA & $\begin{array}{l}\text { Complement } \mathrm{C} 1 \mathrm{q} \\
\text { subcomponent subunit A }\end{array}$ & 2 & 0.61 & 7.75E-04 \\
\hline O55222 & ILK & Integrin-linked protein kinase & 2 & 0.64 & $8.66 \mathrm{E}-03$ \\
\hline P23492 & PNP & Purine nucleoside phosphorylase & 2 & 0.65 & $7.82 \mathrm{E}-03$ \\
\hline Q8CAG6 & PLEK & Pleckstrin & 2 & 0.65 & 9.63E-03 \\
\hline Q5FW60 & MUP20 & Major urinary protein 20 & 2 & 0.66 & 7.91E-03 \\
\hline Q8BPF4 & $\mathrm{N} / \mathrm{A}$ & Putative uncharacterized protein & 3 & 0.67 & 1.69E-02 \\
\hline A2AQ07 & TUBB1 & Tubulin $\beta$-1 chain & 2 & 0.67 & $6.90 \mathrm{E}-04$ \\
\hline P14106 & C1QB & $\begin{array}{l}\text { Complement C1q subcomponent } \\
\text { subunit B }\end{array}$ & 5 & 0.69 & 3.03E-04 \\
\hline P07310 & CKM & Creatine kinase M-type & 4 & 0.7 & $1.86 \mathrm{E}-02$ \\
\hline Q02105 & C1QC & $\begin{array}{l}\text { Complement } \mathrm{C} 1 \mathrm{q} \text { subcomponent } \\
\text { subunit C }\end{array}$ & 4 & 0.7 & 7.42E-03 \\
\hline A7LNR1 & CD93 & CD93 antigen (Fragment) & 2 & 0.7 & $2.26 \mathrm{E}-02$ \\
\hline D3Z0Y2 & PRDX6 & Peroxiredoxin-6 & 3 & 0.71 & 8.35E-03 \\
\hline A2AE89 & GSTM1 & $\begin{array}{l}\text { Glutathione S-transferase } \\
\text { Mu } 1 \text { (Fragment) }\end{array}$ & 2 & 0.71 & $8.21 \mathrm{E}-03$ \\
\hline Q8K0E8 & FGB & Fibrinogen $\beta$ chain & 32 & 0.71 & 2.34E-03 \\
\hline P26039 & TLN1 & Talin-1 & 19 & 0.72 & $2.10 \mathrm{E}-03$ \\
\hline Q923D2 & BLVRB & Flavin reductase (NADPH) & 6 & 0.72 & 4.08E-03 \\
\hline P13634 & CA1 & Carbonic anhydrase 1 & 4 & 0.72 & $3.71 \mathrm{E}-03$ \\
\hline P16015 & CA3 & Carbonic anhydrase 3 & 3 & 0.74 & $3.81 \mathrm{E}-02$ \\
\hline B1AXY5 & B4GALT1 & $\beta$-1,4-galactosyltransferase 1 & 2 & 0.75 & $1.74 \mathrm{E}-02$ \\
\hline P61089 & UBE2N & $\begin{array}{l}\text { Ubiquitin-conjugating } \\
\text { enzyme E2 N }\end{array}$ & 3 & 0.75 & 1.09E-02 \\
\hline P32848 & PVALB & Parvalbumin $\alpha$ & 3 & 0.75 & $2.21 \mathrm{E}-02$ \\
\hline P97336 & OBP1A & $\begin{array}{l}\text { Odorant binding protein Ia } \\
\text { (Fragment) }\end{array}$ & 4 & 0.76 & 7.95E-04 \\
\hline P06909 & $\mathrm{CFH}$ & Complement factor $\mathrm{H}$ & 46 & 1.31 & $9.61 \mathrm{E}-03$ \\
\hline P31532 & SAA4 & Serum amyloid A-4 protein & 7 & 1.32 & 7.37E-03 \\
\hline B2RXW7 & C4B & $\begin{array}{l}\text { Complement component } \\
\text { 4B (Childo blood group) }\end{array}$ & 64 & 1.33 & 7.25E-03 \\
\hline A1L3C5 & PRG4 & Prg 4 protein & 4 & 1.34 & 4.24E-02 \\
\hline P01027 & $\mathrm{C} 3$ & Complement C3 & 107 & 1.34 & $5.16 \mathrm{E}-03$ \\
\hline Q71KU9 & FGL1 & Fibrinogen-like protein 1 & 3 & 1.35 & 3.33E-03 \\
\hline G3X8T9 & SERPINA3N & $\begin{array}{l}\text { Serine (Or cysteine) peptidase } \\
\text { inhibitor, clade A, member } 3 \mathrm{~N} \text {, } \\
\text { isoform CRA_a }\end{array}$ & 18 & 1.37 & $2.41 \mathrm{E}-04$ \\
\hline Q03734 & SERPINA3M & Serine protease inhibitor A3M & 7 & 1.39 & 2.97E-03 \\
\hline Q8BJU6 & COL3A1 & $\begin{array}{l}\text { Putative uncharacterized } \\
\text { protein (Fragment) }\end{array}$ & 3 & 1.39 & 4.46E-02 \\
\hline Q8VCM7 & FGG & Fibrinogen gamma chain & 31 & 1.41 & 5.87E-03 \\
\hline Q9D8W4 & IGLV1 & $\beta$-2-microglobulin & 2 & 1.41 & $5.42 \mathrm{E}-03$ \\
\hline E9PV24 & FGA & Fibrinogen $\alpha$ chain & 37 & 1.41 & 2.95E-03 \\
\hline Q61805 & LBP & $\begin{array}{l}\text { Lipopolysaccharide- } \\
\text { binding protein }\end{array}$ & 4 & 1.42 & $1.40 \mathrm{E}-02$ \\
\hline Q91X72 & HPX & Hemopexin & 25 & 1.53 & $5.85 \mathrm{E}-04$ \\
\hline
\end{tabular}


Table I. Continued.

\begin{tabular}{|c|c|c|c|c|c|}
\hline $\begin{array}{l}\text { UniProt } \\
\text { accession }\end{array}$ & $\begin{array}{c}\text { Gene } \\
\text { symbol }\end{array}$ & Name & $\begin{array}{l}\text { Unique } \\
\text { peptides }\end{array}$ & CUMS/CON & $\begin{array}{c}\text { t-test } \\
\text { P-value }\end{array}$ \\
\hline Q61704 & ITIH3 & $\begin{array}{l}\text { Inter- } \alpha \text {-trypsin inhibitor } \\
\text { heavy chain H3 }\end{array}$ & 19 & 1.6 & $2.74 \mathrm{E}-03$ \\
\hline P61939 & SERPINA7 & Thyroxine-binding globulin & 12 & 1.61 & $4.15 \mathrm{E}-03$ \\
\hline Q60590 & ORM1 & $\alpha$-1-acid glycoprotein 1 & 6 & 1.62 & $1.81 \mathrm{E}-03$ \\
\hline Q91XL1 & LRG1 & Leucine-rich HEV glycoprotein & 6 & 1.74 & $5.48 \mathrm{E}-03$ \\
\hline P12246 & APCS & Serum amyloid P-component & 6 & 1.87 & $3.58 \mathrm{E}-03$ \\
\hline P07361 & ORM2 & $\alpha$-1-acid glycoprotein 2 & 3 & 2.5 & $1.14 \mathrm{E}-04$ \\
\hline Q00898 & SERPINA1E & $\alpha$-1-antitrypsin $1-5$ & 4 & 2.51 & $4.08 \mathrm{E}-03$ \\
\hline Q61646 & $\mathrm{HP}$ & Haptoglobin & 18 & 2.98 & $9.14 \mathrm{E}-04$ \\
\hline
\end{tabular}

CUMS, chronic unpredictable mild stress; CON, control; iTRAQ, isobaric tag for relative and absolute quantitation.

The total distance traveled was not significantly different at baseline, but was significantly shortened after 28 days of CUMS $(\mathrm{P}<0.05)$. Compared to the CON group, immobility time was significantly increased $(\mathrm{P}<0.05)$ and sucrose preference was significantly lower in the CUMS group in the last week $(\mathrm{P}<0.05)$.

Immunodepletion of high-abundance proteins. To assess the efficacy of depletion, equal amounts of sample from each group were loaded onto a one-dimensional electrophoresis gel. After electrophoresis, the gel was stained with Coomassie Blue. More protein bands appeared after immunodepletion comparing with crude plasma samples (Fig. 1). This indicates that immunodepletion is an appropriate method for concentrating low abundance proteins.

Plasma analysis by iTRAQ-based quantitative proteomics. To identify differentially expressed proteins in CUMS mice compared with CON mice, 2D LC-MS/MS coupled with iTRAQ labeling was performed. As all samples from each group were mixed for experimentation, the main concern was systematic variation. It has been published that the iTRAQ approach for identifying and quantifying differentially expressed proteins on a large-scale entails at least a $30 \%$ technical variability (18). Therefore, a 1.3-fold change and unique peptides $\geq 2$ threshold was used, as in our earlier study (5). Using this cut-off threshold, 47 proteins were found to be significantly differentially expressed between the CUMS group and the CON group. Among these 47 proteins, 22 were upregulated and the remainder were downregulated in the CUMS group (Table I).

IPA analysis of the differential proteins. To analyze the overall function of these 47 significantly expressed proteins, we uploaded them onto the IPA server. The top 5 canonical pathways were LXR/RXR activation, acute phase response signaling, FXR/RXR activation, complement system, and intrinsic prothrombin activation pathway (Table II). Four proteins related to these significantly changed canonical pathways were chosen for western blot validation. Additionally, IPA identified the following top five diseases and functions: Cell-to-cell signaling and interaction, developmental disorder,

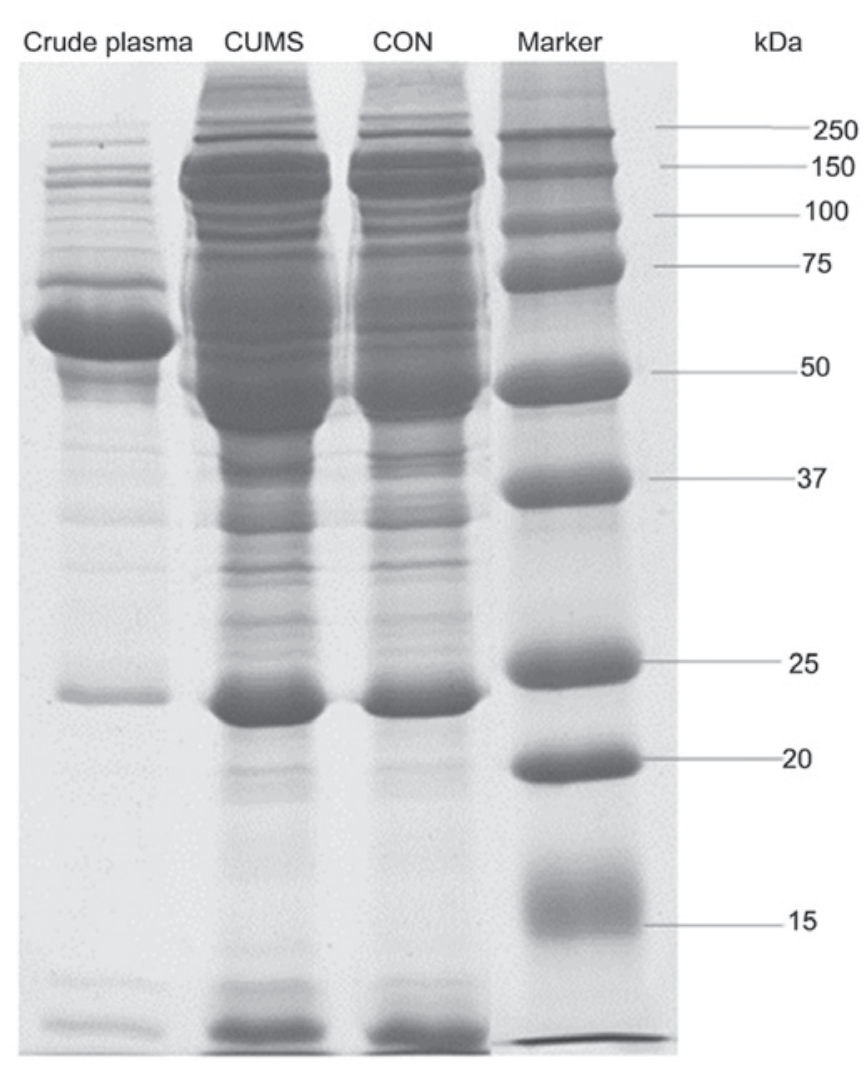

Figure 1. SDS-PAGE was used to assess the efficiency of removal of high-abundance plasma proteins. $20 \mu \mathrm{g}$ of crude plasma (without depletion), CUMS depleted plasma, CON depleted plasma and marker were separated on a $12.5 \%$ SDS-PAGE gel and stained with Coomassie Blue. CUMS, chronic unpredictable mild stress; CON, control.

organismal injury and abnormalities, hereditary disorder, and immunological disease (Table III).

Validation of differential proteins by western blotting. Four significantly changed candidate proteins were chosen for validation using western blotting-lipopolysaccharide-binding protein, fibrinogen $\beta$ chain, $\alpha-1$ antitrypsin, and complement factor $\mathrm{H}$. Compared with the CON group, $\alpha-1$ antitrypsin and 
Table II. Significant differentially changed pathways and related proteins.

\begin{tabular}{lll}
\hline Ingenuity canonical pathways & P-value & Molecules
\end{tabular}

Acute phase response signaling

Complement system

LXR/RXR activation

FXR/RXR activation

Intrinsic prothrombin activation pathway

Coagulation system

Extrinsic prothrombin activation pathway

Role of pattern recognition receptors in recognition of bacteria and viruses

Role of tissue factor in cancer

Xanthine and xanthosine salvage

Atherosclerosis signaling

Guanine and guanosine salvage I

Adenine and adenosine salvage I

Arsenate detoxification I (Glutaredoxin)

Heme degradation

IL-10 signaling

Creatinx-phosphate biosynthesis

Adenine and adenosine salvage III

Purine ribonucleosides degradation to

ribosx-1-phosphate

TR/RXR activation

Guanosine nucleotides degradation III

Urate biosynthesis/inosine 5'-phosphate degradation

Glutaryl-CoA degradation

Phagosome maturation

Adenosine nucleotides degradation II

IL-12 signaling and production in macrophages

Purine nucleotides degradation II (Aerobic)

Germ cell-sertoli cell junction signaling

Glutathione redox reactions I

Tryptophan degradation III (Eukaryotic)

Sertoli cell-sertoli cell junction signaling
$1.00 \mathrm{x}^{-19}$

$1.00 \mathrm{x}^{-10}$

$3.72 \mathrm{x}^{-09}$

$1.70 x^{-07}$

$3.02 \mathrm{x}^{-07}$

$6.61 \mathrm{x}^{-07}$

$3.98 \mathrm{x}^{-06}$

$1.51 \mathrm{x}^{-04}$

$1.82 \mathrm{x}^{-03}$

$2.00 x^{-03}$

$2.04 x^{-03}$

$3.98 \mathrm{x}^{-03}$

$3.98 x^{-03}$

$7.94 x^{-03}$

$7.94 x^{-03}$

$7.94 x^{-03}$

$9.77 x^{-03}$

$1.38 \mathrm{x}^{-02}$

$1.58 \mathrm{x}^{-02}$

$1.62 \mathrm{x}^{-02}$

$2.51 \mathrm{x}^{-02}$

$2.75 \mathrm{x}^{-02}$

$2.95 \mathrm{x}^{-02}$

$3.31 \mathrm{x}^{-02}$

$3.31 \mathrm{x}^{-02}$

$3.39 \mathrm{x}^{-02}$

$3.89 \mathrm{x}^{-02}$

$4.57 \mathrm{x}^{-02}$

$4.68 \mathrm{x}^{-02}$

$4.68 \mathrm{x}^{-02}$

$4.79 \mathrm{x}^{-02}$
HPX, ITIH3, C3, APOA2, SERPINA3, SAA2-

SAA4, FGG, C4A/C4B, HP, APCS, SERPINA, FGB, LBP, FGA

C4A/C4B, C3, C1QA, C1QC, CFH, C1QB

C4A/C4B, HPX, C3, APOA2, SERPINA1, LBP, FGA

C4A/C4B, HPX, C3, APOA2, SERPINA1, FGA

FGB, FGA, FGG, COL3A1

SERPINA1, FGB, FGA, FGG

FGB, FGA, FGG

C3, C1QA, C1QC, C1QB

FGB, FGA, FGG

PNP

APOA2, SERPINA1, COL3A1

PNP

PNP

PNP

BLVRB

BLVRB, LBP

CKM

PNP

PNP

HP, FGA

PNP

PNP

CA1

TUBB1, PRDX6

PNP

APOA2, SERPINA1

PNP

TUBB1, ILK

PRDX6

CA1

TUBB1, ILK

P-value: Fisher's exact test; Molecules: The uploaded proteins mapped to the pathway.

lipopolysaccharide-binding protein were upregulated $(\mathrm{P}<0.05)$ (Fig. 2). In contrast, expression of fibrinogen $\beta$ chain $(\mathrm{P}<0.05)$ was significantly reduced in the CUMS group (Fig. 2). These findings are concordant with our iTRAQ results. However, the expression levels of complement factor $\mathrm{H}$ were not significantly changed as assessed by western blotting ( $\mathrm{P}>0.05$ ) (Fig. 2), although they were significantly upregulated in CUMS mice by the iTRAQ method.

\section{Discussion}

The systemic response triggered by local inflammation, which can be seen in acute and chronic inflammation, is called the acute phase response. The function of acute phase proteins include opsonization, capturing microbes, complement activation, neutralizing enzymes and modulating immune responses. The acute phase proteins validated in this study included LBP, SERPINA1 and FGB, which are involved in the acute phase response pathway (Table II). LBP is used as a marker of a variety of inflammatory diseases and the development and prognosis of disease (19). Furthermore, depression and inflammation are closely related (20). LBP can also affect the innate immune function and Toll-like receptor $4(21,22)$, which are involved in the pathogenesis of depression (23). Thus, LBP might be involved in the pathogenesis of depression. LBP is also associated with other 
Table III. Significant differentially changed diseases and functions with uploaded proteins (top 10).

\begin{tabular}{|c|c|c|}
\hline Category & P-value & Molecules \\
\hline Developmental disorder & $1.43 x^{-10}-3.95 x^{-03}$ & $\begin{array}{l}\text { TUBB1, C3, ILK, C1QA, C1QC, HBA1/HBA2, C1QB, SERPINA7, } \\
\text { FGG, C4A/C4B, CA3, HP, B4GALT1, CST3, APCS, PNP, SERPINA1, } \\
\text { FGB, FGA, CA1, COL3A1 }\end{array}$ \\
\hline Hereditary disorder & $1.43 x^{-10}-3.95 x^{-03}$ & $\begin{array}{l}\text { APOA2, LRG1, C1QA, SERPINA3, C1QC, HBA1/HBA2, C1QB, } \\
\text { SERPINA7, PRDX6, FGG, C4A/C4B, CA3, CST3, APCS, FGB, } \\
\text { SERPINA1, CFH, CA1, TUBB1, PVALB, C3, HP, B4GALT1, PNP, } \\
\text { FGA, COL3A1 }\end{array}$ \\
\hline Immunological disease & $1.43 x^{-10}-3.95 x^{-03}$ & $\begin{array}{l}\text { TUBB1, HPX, C3, C1QA, C1QC, HBA1/HBA2, C1QB, PRDX6, } \\
\text { FGG, C4A/C4B, CA3, HP, B4GALT1, CST3, APCS, PNP, SERPINA1, } \\
\text { FGB, PLEK, LBP, CFH, FGA, CA1, COL3A1 }\end{array}$ \\
\hline $\begin{array}{l}\text { Organismal injury and } \\
\text { abnormalities }\end{array}$ & $1.43 x^{-10}-3.95 x^{-03}$ & $\begin{array}{l}\text { ITIH3, GSTM5, UBE2N, APOA2, LRG1, ILK, C1QC, TLN1, } \\
\text { SERPINA3, C1QA, HBA1/HBA2, C1QB, SERPINA7, PRDX6, FGG, } \\
\text { C4A/C4B, CA3, APCS, CST3, SERPINA1, FGB, LBP, CFH, CA1, } \\
\text { PVALB, TUBB1, HPX, C3, CKM, CD93, BLVRB, HP, B4GALT1, } \\
\text { PNP, FGL1, PLEK, FGA, COL3A1 }\end{array}$ \\
\hline $\begin{array}{l}\text { Cell-To-cell signaling } \\
\text { and interaction }\end{array}$ & $6.08 x^{-10}-3.95 x^{-03}$ & $\begin{array}{l}\text { C3, Ppbp, UBE2N, APOA2, CD93, ILK, C1QA, TLN1, FGG, C4A/ } \\
\text { C4B, B4GALT1, APCS, CST3, PNP, FGB, SERPINA1, PLEK, LBP, } \\
\text { CFH, FGA, COL3A1 }\end{array}$ \\
\hline $\begin{array}{l}\text { Hematological system } \\
\text { development and function }\end{array}$ & $6.08 x^{-10}-3.95 x^{-03}$ & $\begin{array}{l}\text { UBE2N, APOA2, ILK, C1QC, TLN1, SERPINA3, C1QA, HBA1/ } \\
\text { HBA2, FGG, C4A/C4B, APCS, CST3, FGB, SERPINA1, CFH, LBP, } \\
\text { HPX, C3, Ppbp, CD93, HP, B4GALT1, PNP, PLEK, FGA }\end{array}$ \\
\hline Immune cell trafficking & $6.08 x^{-10}-3.95 x^{-03}$ & $\begin{array}{l}\text { C3, Ppbp, UBE2N, CD93, ILK, C1QA, TLN1, SERPINA3, FGG, } \\
\text { C4A/C4B, HP, B4GALT1, CST3, APCS, FGB, SERPINA1, CFH, LBP, } \\
\text { FGA }\end{array}$ \\
\hline Inflammatory response & $7.5 x^{-10}-3.95 x^{-03}$ & $\begin{array}{l}\text { TUBB1, HPX, C3, CKM, APOA2, UBE2N, CD93, ILK, SERPINA3, } \\
\text { TLN1, C1QA, HBA1/HBA2, PRDX6, FGG, C4A/C4B, CA3, HP, } \\
\text { B4GALT1, APCS, CST3, PNP, SERPINA1, FGB, PLEK, CFH, LBP, } \\
\text { FGA, CA1, COL3A1 }\end{array}$ \\
\hline Cellular movement & $6.12 x^{-09}-3.95 x^{-03}$ & $\begin{array}{l}\text { C3, Ppbp, CD93, ILK, TLN1, SERPINA3, PRDX6, C4A/C4B, } \\
\text { HP, B4GALT1, APCS, CST3, SERPINA1, FGB, CFH, LBP, FGA, } \\
\text { COL3A1 }\end{array}$ \\
\hline Hematological disease & $7.18 x^{-09}-3.95 x^{-03}$ & $\begin{array}{l}\text { TUBB1, C3, CKM, APOA2, CD93, C1QA, HBA1/HBA2, FGG, } \\
\text { C4A/C4B, HP, SERPINA1, FGB, FGL1, LBP, PLEK, CFH, FGA }\end{array}$ \\
\hline
\end{tabular}

P-value: Fisher's exact test; Molecules: The uploaded proteins mapped to relevant diseases and functions. The uploaded proteins involved in the Cell-To-Cell Signaling and Interaction are shown in Fig. 3 produced by IPA.

psychiatric disorders, such as Parkinson's disease (24), and therefore, LBP may be closely related to central nervous system functions. The concentration of SERPINA1 in the plasma of depressed patients is increased (25), consistent with our results. SERPINA1 also has a relationship with the immune system, the apoptotic process and the inflammatory response (26). The concentration of FGB is reduced in the platelets of depressed patients (27), also consistent with our results. This suggests that FGB is closely related to the occurrence and development of depression. The plasma concentration of FGB is also abnormal in Rett syndrome (28), and Rett syndrome is a unusual genetic postnatal neurological disease negatively affecting the grey matter of the brain. Thus, FGB may be closely related to central nervous system functions.

Retinoid X receptors (RXRs) are nuclear receptors that mediate the biological effects of retinoids. $\mathrm{RXR} \alpha$ is the dimerization partner for the type II nuclear receptors that include the liver $\mathrm{X}$ receptor (LXR). The LXR is activated by oxysterol ligands and forms a heterodimer with RXR. After the heterodimer is formed, LXR initiates the transcription of the target gene by binding to the LXR response element. LXR/RXR are involved in lipid metabolism, the inflammatory response and cholesterol and bile acid metabolism (29). Previous studies suggest that abnormalities in these processes lead to the development of depression $(9,20)$. The farnesoid $X$ receptor (FXR) is a member of the nuclear receptor family and is a key player in many metabolic pathways. FXR is activated by bile acids and their intermediates, which thus serves as a sensor of bile acid levels. Along with the retinoid $\mathrm{X}$ receptor (RXR), FXR plays a key role in linking bile acid regulation with lipoprotein and lipid and glucose metabolism (30). Energy metabolism is dysregulated in depressed patients and in the CUMS mouse model $(5,10,11)$. Perturbations of the 


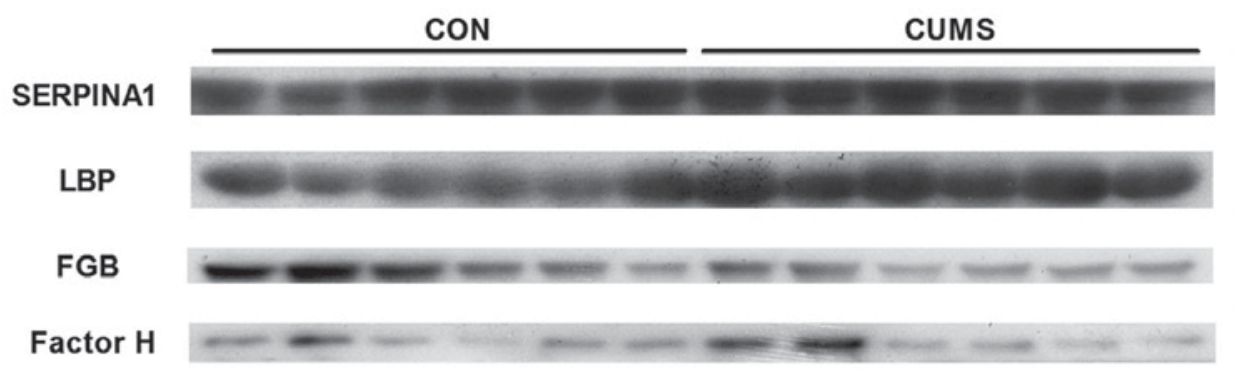

Factor $\mathrm{H}$

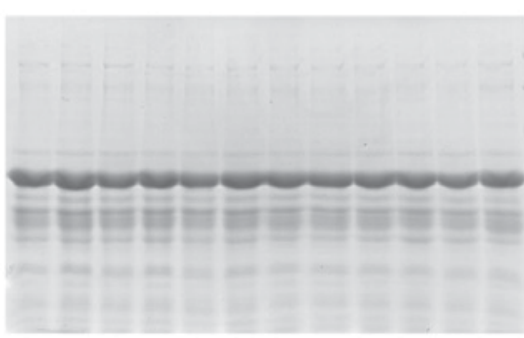

Loading control
SERPINA1

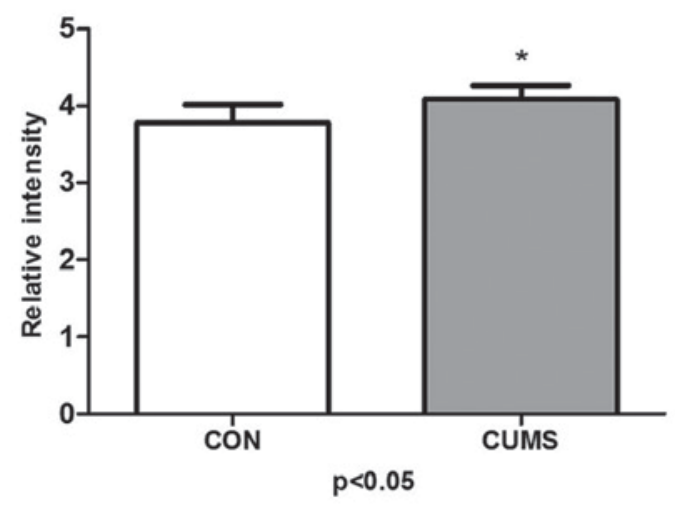

FGB

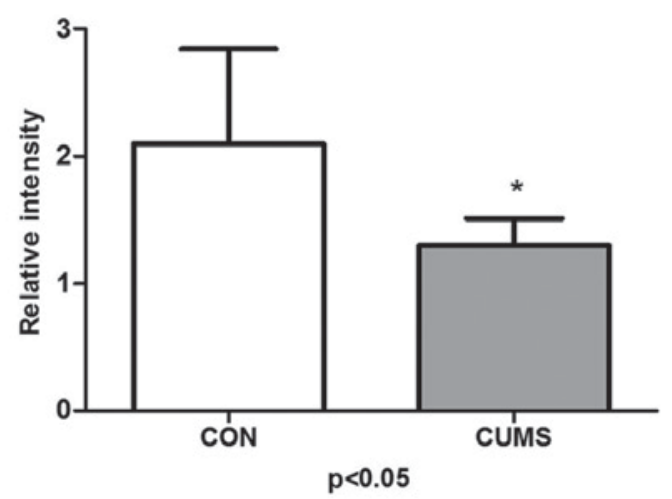

Factor $\mathrm{H}$

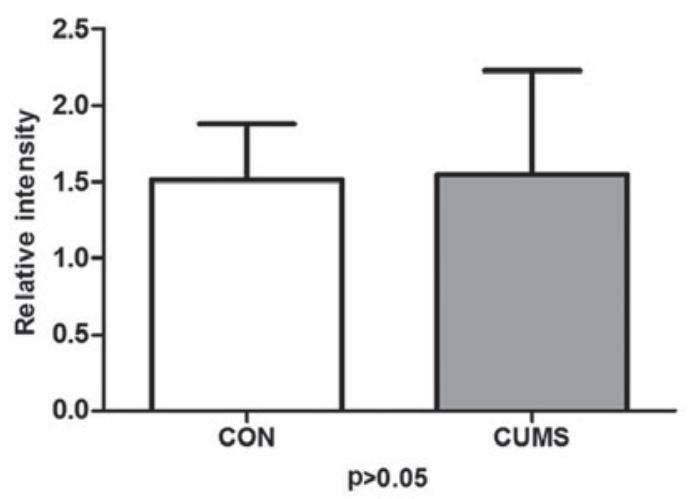

Figure 2. Western blotting validation results of lipopolysaccharide-binding protein (LBP) ( $\mathrm{P}<0.001$ vs. CON), fibrinogen- $\beta$ chain (FGB) ( $\mathrm{P}=0.030$ vs. CON), $\alpha-1$ antitrypsin (SERPINA1) ( $\mathrm{P}=0.033$ vs. $\mathrm{CON}$ ) and Factor $\mathrm{H}(\mathrm{P}=0.910$ vs. $\mathrm{CON})$. All samples were validated in triplicate. A loading control was used for normalizing protein amounts. CUMS ( $\mathrm{n}=6)$, chronic unpredictable mild stress; $\mathrm{CON}(\mathrm{n}=6)$, control.

LXR/RXR and FXR/RXR pathways may be involved in the development of depression $(31,32)$. In this study, according to the IPA, iTRAQ data and western blotting validation, LBP is involved in LXR/RXR activation (Table II), in accordance with a previous study (33). SERPINA1 is also related to the LXR/RXR and FXR/RXR pathways (Table II). Thus, LBP and SERPINA1 might be responsible for the occurrence and development of MDD via LXR/RXR and FXR/RXR pathways.

According to IPA analysis and previous studies, LBP is also involved in IL-10 signaling (34). FGB is related to the coagulation system, the extrinsic prothrombin activation pathway, and role of tissue factor in cancer (35). SERPINA1 participates in the coagulation system (36), atherosclerotic signaling (37), and IL-12 signaling and production in macrophages (Table II) (38). This suggests that these pathways likely contribute to the development of depression.

The various changes in proteins and pathways in the CUMS model might ultimately lead to a depressive state. In this study, the first five significantly changed functions and diseases identified by IPA were cell-to-cell signaling and interaction, developmental disorder, organismal injury and abnormalities, hereditary disorder, and immunological disease (Table III). These results suggest that depression is also related 


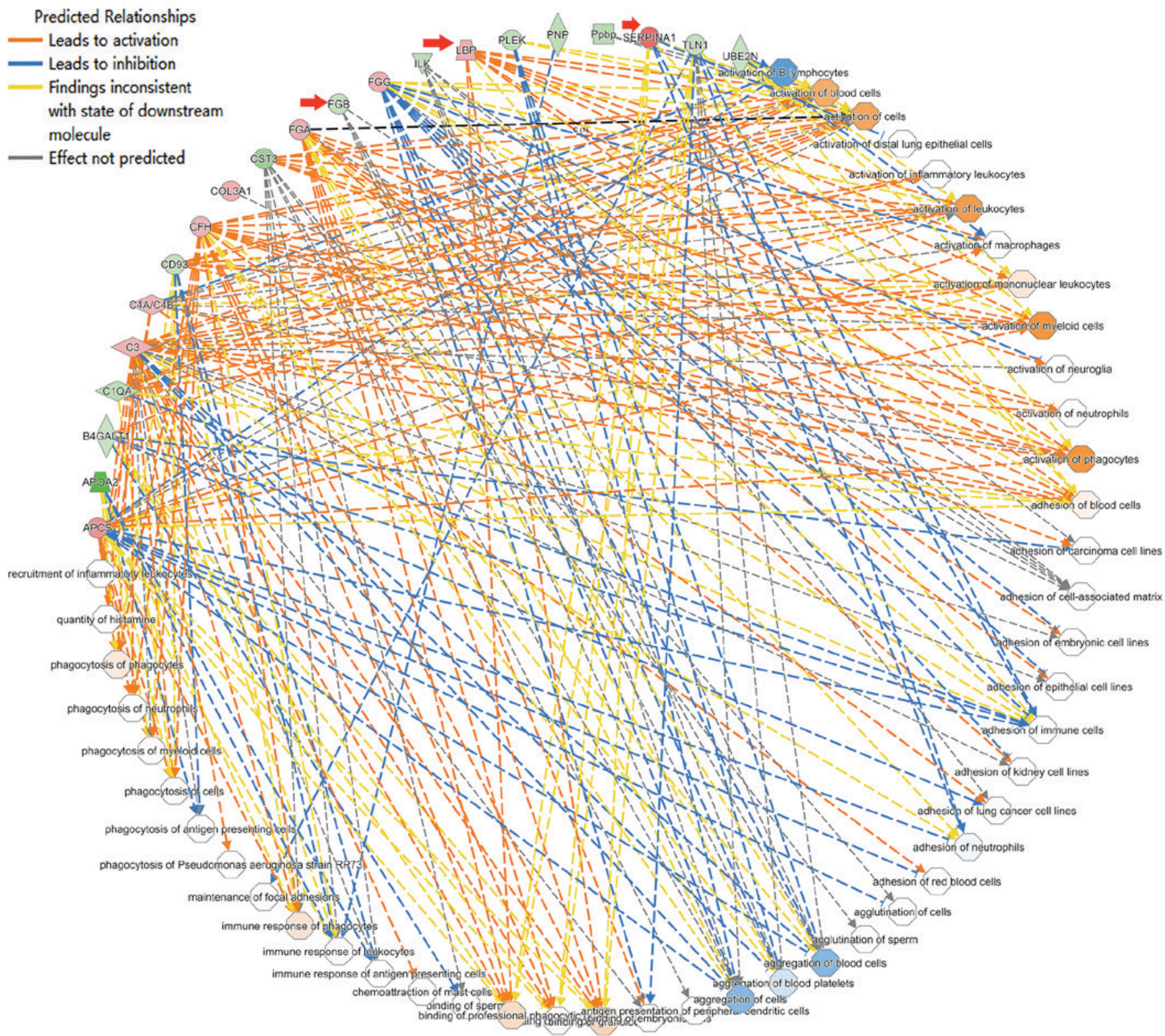

Figure 3. The uploaded proteins involved in intercellular interactions and signaling are shown in this diagram produced by IPA. Green and red protein nodes represent decreased and increased levels, respectively, in the CUMS group. Each protein node is connected to the relevant disease and functional nodes. Nodes of diseases and functions in blue indicate predicted inhibition, while those in yellow indicate predicted activation. The deeper the color, the stronger the activity. Arrows in red point to the proteins validated in this study.

to structural abnormalities in the central nervous system (39) as well as intercellular interaction and signal transmission (Fig. 3). Therefore, synaptic neurotransmission might be perturbed in CUMS mice.

However, the expression levels of factor $\mathrm{H}$ were not significantly changed as assessed by western blotting, although they were significantly upregulated in CUMS mice by the iTRAQ method. A similar phenomenon has also been observed in other previous studies $(5,6)$. The variability of dynamic range between ITRAQ and western blotting and the internal differences related to the steps of iTRAQ coupled with tandem mass spectrometry approach and western blotting analysis may lead to this discrepancy.

These results suggest that the CUMS mouse model is a suitable model of depression, and that peripheral plasma samples can, at least to an extent, provide some biomarkers of depression. The three significantly differentially expressed proteins (FGB, SERPINA1, LBP) are worthy of further studies on the molecular mechanisms of depression.

\section{Acknowledgements}

This study was financially supported by The National Key Research and Development Program of China (grant no. 2017YFA0505700), The Natural Science Foundation Project of China (grant no. 81371310), and Funds for Outstanding Young Scholars in Chongqing Medical University (grant no. CYYQ201502). We thank Barry Patel, $\mathrm{PhD}$, from Liwen Bianji, Edanz Group China (www.liwenbianji.cn/ac), for editing the English text of a draft of this manuscript. 


\section{References}

1. Bakish D: New standard of depression treatment: Remission and full recovery. J Clin Psychiatry 62 (Suppl 26): S5-S9, 2001.

2. Greenberg PE, Fournier AA, Sisitsky T, Pike CT and Kessler RC: The economic burden of adults with major depressive disorder in the United States (2005 and 2010). J Clin Psychiatry 76: 155-162, 2015.

3. Bennett S and Thomas AJ: Depression and dementia: Cause, consequence or coincidence? Maturitas 79: 184-190, 2014.

4. Belmaker RH and Agam G: Major depressive disorder. N Engl J Med 358: 55-68, 2008.

5. Xu HB, Zhang RF, Luo D, Zhou Y, Wang Y, Fang L, Li WJ, Mu J, Zhang L, Zhang Y and Xie P: Comparative proteomic analysis of plasma from major depressive patients: Identification of proteins associated with lipid metabolism and immunoregulation. Int J Neuropsychopharmacol 15: 1413-1425, 2012.

6. Yang Y, Chen J, Liu C, Fang L, Liu Z, Guo J, Cheng K, Zhou C, Zhan Y, Melgiri ND, et al: The extrinsic coagulation pathway: A biomarker for suicidal behavior in major depressive disorder. Sci Rep 6: 32882, 2016.

7. Song YR, Wu B, Yang YT, Chen J, Zhang LJ, Zhang ZW, Shi HY, Huang CL, Pan JX and Xie P: Specific alterations in plasma proteins during depressed, manic, and euthymic states of bipolar disorder. Braz J Med Biol Res 48: 973-982, 2015.

8. Hinze-Selch D, Schuld A, Kraus T, Kühn M, Uhr M, Haack M and Pollmächer T: Effects of antidepressants on weight and on the plasma levels of leptin, TNF- $\alpha$ and soluble TNF Receptors: A longitudinal study in patients treated with amitriptyline or paroxetine. Neuropsychopharmacology 23: 13-19, 2000.

9. Wu Y, Tang J, Zhou C, Zhao L, Chen J, Zeng L, Rao C, Shi H, Liao L, Liang Z, et al: Quantitative proteomics analysis of the liver reveals immune regulation and lipid metabolism dysregulation in a mouse model of depression. Behav Brain Res 311: 330-339, 2016

10. Rao C, Shi H, Zhou C, Zhu D, Zhao M, Wang Z, Yang Y, Chen J, Liao L, Tang J, et al: Hypothalamic proteomic analysis reveals dysregulation of glutamate balance and energy metabolism in a mouse model of chronic mild stress-induced depression. Neurochem Res 41: 2443-2456, 2016.

11. Cheng K, Li J, Yang D, Yang Y, Rao C, Zhang S, Wang W, Guo H, Fang L, Zhu D, et al: 2D-gel based proteomics unravels neurogenesis and energetic metabolism dysfunction of the olfactory bulb in CUMS rat model. Behav Brain Res 313: 302-309, 2016.

12. Yang Y, Yang D, Tang G, Zhou C, Cheng K, Zhou J, Wu B, Peng Y, Liu C, Zhan Y, et al: Proteomics reveals energy and glutathione metabolic dysregulation in the prefrontal cortex of a rat model of depression. Neuroscience 247: 191-200, 2013.

13. Moussa E, Huang H, Ahras M, Lall A, Thezenas ML, Fischer R, Kessler BM, Pain A, Billker O and Casals-Pascual C: Proteomic profiling of the brain of mice with experimental cerebral malaria. J Proteomics: Jun 5, 2017 (Epub ahead of print).

14. Niklasson $\mathrm{F}$ and Agren $\mathrm{H}$ : Brain energy metabolism and blood-brain barrier permeability in depressive patients: Analyses of creatine, creatinine, urate, and albumin in CSF and blood. Bio Psychiatry 19: 1183-1206, 1984.

15. Li J, Zhang SX, Wang W, Cheng K, Guo H, Rao CL, Yang DY, He Y, Zou DZ, Han Y, et al: Potential antidepressant and resilience mechanism revealed by metabolomic study on peripheral blood mononuclear cells of stress resilient rats. Behav Brain Res 320: 12-20, 2017.

16. Guest PC, Guest FL and Martins-de Souza D: Making sense of blood-based proteomics and metabolomics in psychiatric research. Int J Neuropsychopharmacol: Dec 30, 2015 (Epub ahead of print)

17. Wisniewski JR, Zougman A, Nagaraj N and Mann M: Universa sample preparation method for proteome analysis. Nat Methods 6: 359-362, 2009

18. Gan CS, Chong PK, Pham TK and Wright PC: Technical, experimental and biological variations in isobaric tags for relative and absolute quantitation (iTRAQ). J Proteome Res 6: 821-827, 2007.

19. Brănescu C, Şerban D, Şavlovschi C, Dascălu AM and Kraft A: Lipopolysaccharide binding protein (L.B.P.)-an inflammatory marker of prognosis in the acute appendicitis. J Med Life 5: 342-347, 2012.

20. Berk M, Williams LJ, Jacka FN, O'Neil A, Pasco JA, Moylan S, Allen NB, Stuart AL, Hayley AC, Byrne ML and Maes M: So depression is an inflammatory disease, but where does the inflammation come from? BMC Med 11: 200, 2013.
21. Ding PH and Jin LJ: The role of lipopolysaccharide-binding protein in innate immunity: A revisit and its relevance to oral/periodontal health. J Periodontal Res 49: 1-9, 2014.

22. Pahwa R, Devaraj S and Jialal I: The effect of the accessory proteins, soluble CD14 and lipopolysaccharide-binding protein on Toll-like receptor 4 activity in human monocytes and adipocytes. Int J Obes (Lond) 40: 907-911, 2016.

23. Liu J, Buisman-Pijlman F and Hutchinson MR: Toll-like receptor 4: Innate immune regulator of neuroimmune and neuroendocrine interactions in stress and major depressive disorder. Front Neurosci 8: 309, 2014

24. Pal GD, Shaikh M, Forsyth CB, Ouyang B, Keshavarzian A and Shannon KM: Abnormal lipopolysaccharide binding protein as marker of gastrointestinal inflammation in Parkinson disease. Front Neurosci 9: 306, 2015.

25. Joyce PR, Hawes CR, Mulder RT, Sellman JD, Wilson DA and Boswell DR: Elevated levels of acute phase plasma proteins in major depression. Biol Psychiatry 32: 1035-1041, 1992.

26. de Serres F and Blanco I: Role of alpha-1 antitrypsin in human health and disease. J Intern Med 276: 311-335, 2014.

27. Huang TL, Sung ML and Chen TY: 2D-DIGE proteome analysis on the platelet proteins of patients with major depression. Proteome Sci 12: 1, 2014.

28. Cortelazzo A, Guerranti R, De Felice C, Signorini C, Leoncini S, Pecorelli A, Landi C, Bini L, Montomoli B, Sticozzi C, et al: A plasma proteomic approach in Rett syndrome: Classical versus preserved speech variant. Mediators Inflamm 2013: 438653, 2013.

29. Edwards PA, Kennedy MA and Mak PA: LXRs; oxysterol-activated nuclear receptors that regulate genes controlling lipid homeostasis. Vascul Pharmacol 38: 249-256, 2002.

30. Rizzo G, Renga B, Mencarelli A, Pellicciari R and Fiorucci S: Role of FXR in regulating bile acid homeostasis and relevance for human diseases. Curr Drug Targets Immune Endocr Metabol Disord 5: 389-303, 2005.

31. Jia P, Kao CF, Kuo PH and Zhao Z: A comprehensive network and pathway analysis of candidate genes in major depressive disorder. BMC Syst Biol 5 (Suppl 3): S12, 2011.

32. Steri R, Achenbach J, Steinhilber D, Schubert-Zsilavecz M and Proschak E: Investigation of imatinib and other approved drugs as starting points for antidiabetic drug discovery with FXR modulating activity. Biochem Pharmacol 83: 1674-1681, 2012.

33. Li GC, Zhang L, Yu M, Jia H, Tian T, Wang J, Wang F and Zhou L: Identification of novel biomarker and therapeutic target candidates for acute intracerebral hemorrhage by quantitative plasma proteomics. Clin Proteomics 14: 14, 2017.

34. Ren L, Jiang ZQ, Fu Y, Leung WK and Jin L: The interplay of lipopolysaccharide-binding protein and cytokines in periodontal health and disease. J Clin Periodontol 36: 619-626, 2009.

35. Choe H, Sboner A, Beltran H, Nanus D and Tagawa ST: PO-43 - Differential coagulation factor expression in neuroendocrine prostate cancer (PC), metastatic castrate-resistant PC, and localized prostatic adenocarcinoma. Thromb Res 140 (Suppl 1): S192, 2016.

36. Langley PG, Hughes RD, Rolando N and Williams R: Increased elastase-alpha 1-antitrypsin complex in fulminant hepatic failure: Relationship to bacterial infection and activation of coagulation. Clin Chim Acta 200: 211-219, 1991.

37. Howlett GJ and Moore KJ: Untangling the role of amyloid in atherosclerosis. Curr Opin Lipidol 17: 541-547, 2006.

38. Subramaniyam D, Steele C, Köhnlein T, Welte T, Grip O, Matalon S and Janciauskiene S: Effects of alpha 1-antitrypsin on endotoxin-induced lung inflammation in vivo. Inflamm Res 59: 571-578, 2010.

39. Cheng W, Rolls ET, Qiu J, Liu W, Tang Y, Huang CC, Wang X, Zhang J, Lin W, Zheng L, et al: Medial reward and lateral non-reward orbitofrontal cortex circuits change in opposite directions in depression. Brain 139: 3296-3309, 2016.

This work is licensed under a Creative Commons Attribution-NonCommercial-NoDerivatives 4.0 International (CC BY-NC-ND 4.0) License. 